\title{
ESTUDO SOBRE O USO CONSORCIADO DE ENERGIA SOLAR FOTOVOLTAICA COM BIOMASSA EM GRANJAS DE FRANGO DE CORTE
}

Fernando Barbosa Matos

Instituto Federal Goiano - IFG, campus de Morrinhos, GO. E-mail: fernando.matos@ifgoiano.edu.br

\section{RESUM 0}

Este artigo trata da análise da viabilidade financeira do uso consorciado de energia solar fotovoltaica com a biomassa produzida a partir de um biodigestor. Esses dois meios de geração de energia alternativa são apropriados para utilização em granjas de frango de corte, reaproveitando a cama de frango e permitindo ao produtor diversificar sua produção através da venda de biofertilizante produzido na granja. Esse complemento de receita é que torna o empreendimento viável, fazendo com que a taxa de retorno interno seja superior a taxa mínima de atratividade.

Palavras - chave: biodigestor; cogeração de energia; granja de frango de corte; energia fotovoltaica.

\section{STUDY ON THE CONSORTIATIVE USE OF PHOTOVOLTAIC SOLAR ENERGY WITH BIOMASS IN CUT CHICKEN FARMS}

\begin{abstract}
This paper proposes an analysis of the financial viability of the consortium use of photovoltaic solar energy with the biomass produced from a biodigester. These two means of alternative energy generation are suitable for use in chicken farms, reusing the chicken bed and allowing the producer to diversify his production through the sale of biofertilizer produced on the farm. This revenue complement is what makes the enterprise viable, making the internal rate of return higher than the minimum rate of attractiveness.
\end{abstract}

Keywords: biodigester; energy co-generation; chicken farm; photovoltaic power.

\section{INTRODUÇÃO}

A criação de frango de corte no brasil é uma das principais atividades do agronegócio brasileiro, com um plantel anual estimado em 5,96 bilhões de cabeças, sendo que a Região Sul respondeu por $60,7 \%$ do abate nacional de frangos no 20 trimestre de 2016 , seguida pelas Regiões Sudeste (19,9\%), Centro-Oeste (14,0\%), Nordeste (3,7\%) e Norte $(1,6 \%)$ (IBGE, 2016).

0 Brasil apresenta um forte mercado interno no consumo da carne de frango, sendo estimado pela Associação Brasileira dos Produtores de Pintos de Corte (APINCO) e pelo Instituto Brasileiro de Geografia e Estetística (IBGE) em 46,1 kg por habitante anual. Esse número supera 0 consumo de carne bovina (39,8 kg por habitante anual) e de carne suína (14,7 kg por habitante anual) se consolidando como principal fonte de proteína animal consumida pela população brasileira.

Da mesma forma, o mercado externo é um grande consumidor do frango de corte brasileiro. Segundo a Secretaria de Comercio Exterior (SECCEX) o Brasil exportou em 2015 cerca de 4.045 mil toneladas de frango o que representou uma receita para o setor de cerca de 6,6 bilhões de dólares. Os principais destinos para a carne de frango brasileira são respectivamente a Arábia 
Saudita (17,8\%), China (14,2\%), Japão (9,7\%), Emirados Árabes (6,6\%) e Hong Kong (5,8\%) do total de exportações (IBGE, 2016).

Diante dos números expostos é fácil verificar a importância do frango de corte para 0 agronegócio e consequentemente para a economia brasileira, frente ao seu impacto no Produto Interno Bruto (PIB) e na importância desse recurso no prato alimentar do brasileiro.

A produção de frango de corte se dá em granjas que possuem equipamentos elétricos para controlar a temperatura, a umidade, a distribuição de ração e o controle biossanitário. Isso devido ao fato de que durante o ciclo de vida do frango, este é muito sensível a mudanças bruscas em seu meio ambiente, vindo rapidamente a óbito. Essa característica do animal pode levar rapidamente a um cenário em que a degradação dos controles ambientais podem se traduzir na dizimação de todo um rebanho, gerando grandes prejuízos ao produtor. Essa situação é crítica no que se refere a temperatura, como pode ser verificada na Figura 1.

Figura 1. Zona de termoneutralidade. Região de temperatura onde o calor dissipado pela ave está em equilíbrio com o meio ambiente. Fonte (Ferreira, 2015)

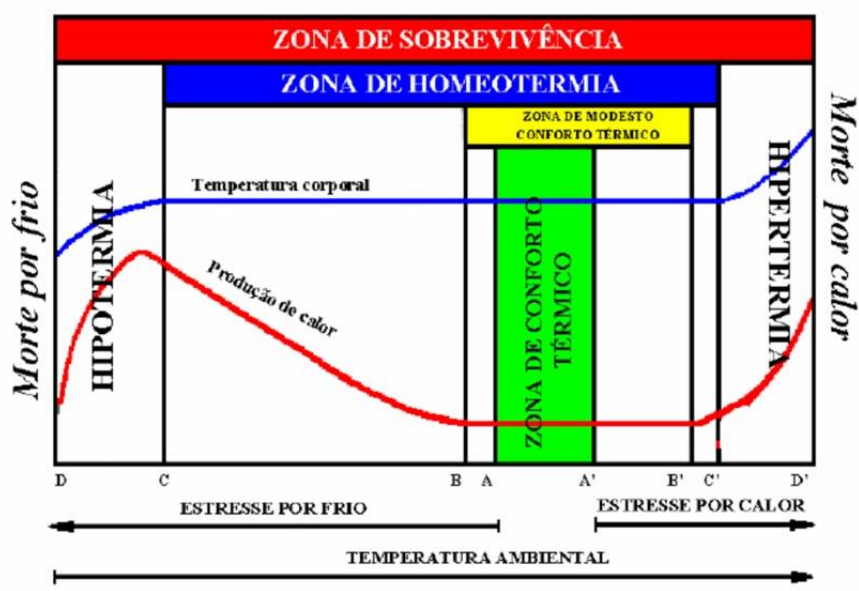

Da Figura 1 é possível observar que a zona de conforto térmico para a ave está compreendido entre o intervalo de $\mathbf{A}$ e $\mathbf{A}^{\prime}$ que seria a região ideal para a operação da granja, pois nesse intervalo, as aves estão propensas a ganhar mais peso e consumir menos ração por não estar numa região de estresse térmico.

O intervalo compreendido entre $\mathbf{B}$ e $\mathbf{B}^{\prime}$ (excluindo o intervalo entre $A$ e $A^{\prime}$ ) é considerado uma zona de relativo ou modesto conforto térmico. Nessa zona a ave está sujeita a uma maior transpiração se a temperatura estiver no intervalo de $\mathbf{A}^{\prime}$ a $\mathbf{B}^{\prime}$. Essa situação favorece a perda de peso e o menor crescimento da ave, o que comprometerá de maneira moderada seu peso final de abate. Já se a temperatura estiver no intervalo entre $\mathbf{B}$ e $\mathbf{A}$, a ave estará propensa a consumir mais ração, o que impacta nos custos de produção do lote em questão.

0 intervalo compreendido entre os pontos $\mathbf{C}$ e $\mathbf{C}^{\prime}$ (Excluindo o intervalo entre $\mathrm{B}$ e $\mathrm{B}^{\prime}$ ) é denominada zona de homeotermia. Nessa região as aves estão sobre grande estresse térmico prejudicando seu peso e seu crescimento, com temperaturas no intervalo entre $\mathbf{B}^{\prime}$ e $\mathbf{C}^{\prime}$, ou 0 aumento no consumo da ração aliado ao baixo desenvolvimento das aves se as temperaturas estiverem compreendidas no intervalo entre $\mathbf{B}$ e $\mathbf{C}$.

A zona de sobrevivência das aves está delimitadas por temperaturas compreendidas entre D e $\mathbf{D}^{\prime}$. Sendo o intervalo de temperaturas entre $\mathbf{D}$ e $\mathbf{C}$ a região de hipotermia e a região entre $\mathbf{C}^{\prime}$ e $\mathbf{D}^{\prime}$ de hipertermia. Ambas de extremo estresse térmico para a ave. Temperaturas inferiores a $\mathbf{D}$ ou 
superiores a $\mathbf{D}^{\prime}$ levam a ave a óbito. Os coeficientes $\mathbf{A}, \mathbf{A}^{\prime}, \mathbf{B}, \mathbf{B}^{\prime}, \mathbf{C}, \mathbf{C}^{\prime}, \mathbf{D}, \mathbf{D}^{\prime}$ variam de acordo com a idade do frango para abate no período de 0 (zero) a 42 dias (FERREIRA, 2015).

Como esses equipamentos para o controle ambiental e biossanitário dependem quase que exclusivamente da energia elétrica fornecida pela concessionária local, uma interrupção de energia por um período superior a 4 horas pode levar ao colapso completo do sistema de controle ambiental da granja, levando a temperatura rapidamente para fora dos limites da zona de sobrevivência das aves (compreendidos entre $\mathbf{D}$ e $\mathbf{D}$ '), e consequentemente levando-as a óbito.

Segundo o Relatório de Evento em Situação de Emergência (AES Eletropaulo, 2016) da Eletropaulo, em 2016 houve um tempo de interrupção médio de energia de 3,61 horas em 22 municípios do estado de São Paulo devido a eventos meteorológicos que impactaram 0 fornecimento de energia pela concessionária elétrica. Essa situação mostra como é perigoso para o produtor depender apenas da energia elétrica fornecida pela concessionária.

$\mathrm{Na}$ contramão desse cenário, o produtor conta a seu favor inúmeros recursos naturais que podem ser utilizados como fontes alternativas de energia, seja para servir como um sistema de backup em caso de falha do sistema elétrico, seja para minimizar custos envolvidos na cadeia produtiva do frango de corte.

As principais fontes de energia alternativa que podem ser utilizados na produção de frango de corte em praticamente todas as regiões do Brasil são a energia solar fotovoltaica, a energia solar térmica e a energia da biomassa gerada pela cama de frango por meio de biodigestores. Já fontes como a eólica e a hídrica dependem de características específicas de cada propriedade e região, como regime de ventos, quantidade e tipo de recursos hídricos. Por tanto não se mostram como uma alternativa para produtores em geral.

Assim os objetivos desse estudo são a caracterização da energia solar fotovoltaica, e sua utilização consorciada com biodigestores na cadeia produtiva do frango de corte, o levantamento da viabilidade econômica para a construção e/ou modernização de granjas aliadas ao tempo de retorno do investimento para o empreendimento.

\section{MATERIAIS E MÉTODOS}

\subsection{Energia Solar}

A sociedade moderna faz extensivo uso das fontes de energia para sua sustentabilidade, para a execução das suas atividades diárias, para a produção de bens e serviços, assim como é utilizada para o conforto dos seus indivíduos. Dentre as formas de energia destacam-se o petróleo, carvão mineral, gás natural, energia nuclear e energia hidroelétrica (M ATOS, 2006).

Da mesma forma, no caso da energia solar, o Brasil apresenta uma grande vantagem, pois a média de insolação para o aproveitamento da luz para a geração de energia elétrica está na faixa de 5 a 7 horas diárias em praticamente todo território nacional, ou seja, o Brasil é banhado com mais de $2000 \mathrm{kWh} / \mathrm{m}^{2}$ por ano, como está descrito em (M ATOS, 2006).

Embora a sustentabilidade seja a tendência para o futuro das nações, o uso em larga escala de fontes, hoje denominadas de energia alternativa, só serão implantadas caso seja comprovada sua viabilidade técnica e principalmente econômica. Cada fonte energética possui um conjunto de características particulares e peculiares que vão influenciar na sua utilização, rendimento e viabilidade econômica, sendo esta última o principal fator preponderante para sua utilização (M ATOS, 2006).

Dentre as fontes de energia alternativa destaca-se a energia solar fotovoltaica. 0 efeito fotovoltaico ocorre em painéis construídos com material semicondutor, geralmente a base de silício, esses painéis transformam a luz solar do espectro visível em eletricidade e tem uma eficiência característica de cerca de $14 \%$ a $18 \%$. Os painéis produzem eletricidade em corrente contínua, tipicamente entre 12 a 48 volts e uma corrente de 8 a 30 amperes (MATOS, 2006). Os painéis fotovoltaicos são interligados a controladores de carga que vão estabilizar as variações 
elétricas provocadas pela variação da luminosidade solar em decorrência da posição do sol durante o dia ou da passagem de nuvens sobre a placa. Um sistema fotovoltaico completo é formado pelas placas solares, por controladores de caraga, inversores e baterias. Quando o sistema de energia solar está conectado a rede concessionária elétrica, esse sistema é denominado de grid tie. A Figura 2 apresenta um sistema Fotovoltaico grid tie típico.

Figura 2. Configuração típica de um sistema Grid Tie. Fonte: site R3 Técnica.

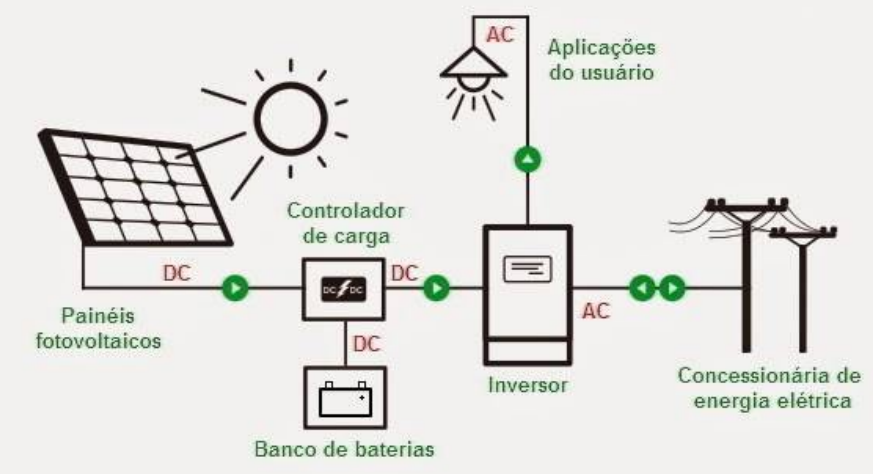

\subsection{Cogeração de Energia por Biomassa em Biodigestores}

A cogeração de energia é uma solução de engenharia, aplicável para determinados usuários de energia, que pode, em determinadas condições, viabilizar economicamente a autoprodução de energia (BRASIL, 2005). A autoprodução de energia é definida como sendo a geração de energia elétrica junto aos centros de carga do próprio consumidor.

Conceitualmente, a cogeração de energia elétrica está associada ao uso de energia térmica, proveniente do resultado de um processo de produção, para a geração complementar de eletricidade. Porém, não seria incorreto afirmar que o uso do gás metano $\left(\mathrm{CH}_{4}\right)$ proveniente de um biodigestor, abastecido com cama de frango, que é um subproduto do processo de criação do frango de corte, para a geração energia elétrica, seria um tipo de processo de cogeração. Isso devido ao fato que 0 uso do gás $\mathrm{CH}_{4}$ para a geração de eletricidade pode ser utilizado tanto para a queima numa caldeira para movimentar uma turbina a vapor, quanto usado diretamente num grupo gerador elétrico.

$\mathrm{Na}$ avicultura de corte, são gerados subprodutos, considerados inicialmente como resíduos, como o caso da cama de frango. Com o devido manejo, pode ser uma importante fonte de renda e agregação de valor à atividade de criação de frango de corte (SARM ENTO et. al., 2015).

O Biodigestor é onde a biomassa sofre a digestão pelas bactérias anaeróbicas, num processo de fermentação gerando gás e biofertilizante. Consiste num recipiente fechado, construído de alvenaria, concreto, polietileno entre outros materiais, onde é depositado o material a ser digerido. 0 processo de decomposição da matéria orgânica resulta na produção de biogás, geralmente 0 gás metano $\left(\mathrm{CH}_{4}\right)$ e biofertilizante conforme apresentado na Figura 3 (CERVI et. al., 2010). 
Figura 3. Biodigestor modelo Indiano. Fonte: CERVI et. al., 2010

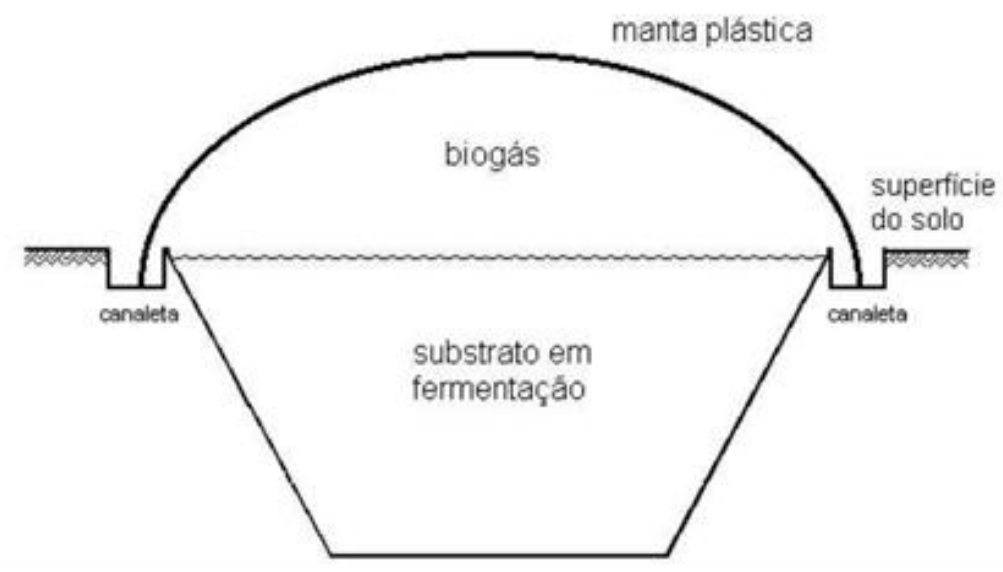

Como descrito em Sarmento et. al. (2015) a biodigestão é realizada por bactérias da cama de frango, e acontece através de um processo natural quando a mesma se encontra num ambiente sem oxigênio (anaeróbico). Após passar pelo biodigestor, a cama de frango se decompõe em três unidades básicas. Uma fração gasosa denominada de biogás, uma líquida denominada biofertilizante e outra sólida.

O biogás é uma mistura de vários tipos de gases, que pode ser queimado diretamente em fogões, motores, caldeiras ou grupo geradores para geração energia elétrica e pode Substituir tanto 0 gás de botijão (butano $-\mathrm{C}_{4} \mathrm{H}_{10}$ ), a lenha, querosene ou gasolina. Já o biofertilizante é um adubo líquido rico em nutrientes para o crescimento de plantas (SARM ENTO et. al., 2015).

\subsection{Viabilidade Econômica}

A viabilidade econômica para a implantação no uso de fontes alternativas de energia, como no caso da energia solar ou do biogás num biodigestor, deve ser o grande fator a ser considerado ao se realizar um investimento de atualização, reforma ou mesmo a construção de uma granja de corte a partir da planta. Isso devido ao grande valor de capital financeiro imobilizado no empreendimento. De acordo com a Cervi (2009) cada produtor deve medir os seus próprios consumos específicos e identificar os meios de otimizá-los.

Nesse sentido, uma forma para calcular o levantamento da viabilidade econômica da implantação do uso de fontes alternativas de energia na produção do frango de corte é a utilização de um conjunto de fórmulas matemáticas aplicadas ao setor financeiro.

A base de todas as técnicas de análise de investimentos é o fluxo de caixa segundo Madeira (2008). Essa técnica é uma representação gráfica de entradas e saídas de recursos monetários ao longo de um determinado período, ou seja, uma demonstração visual de receitas e despesas distribuídas pela linha do tempo futuro. Conforme apresentado na Figura 4.

Figura 4. Exemplo da representação gráfica do fluxo de caixa. Fonte: Madeira (2008)

\begin{tabular}{|c|c|c|c|c|c|}
\hline & & 150 & 450 & & $\mathrm{vF}=100$ \\
\hline $\mathrm{vP}=100$ & & $\uparrow$ & $\uparrow$ & & $\uparrow$ \\
\hline $\mathbf{0}$ & $\mathbf{1}$ & $\mathbf{2}$ & $\mathbf{3}$ & $\mathbf{4}$ & $\mathbf{5}$ \\
\hline$\downarrow$ & $\downarrow$ & & & $\downarrow$ & \\
\hline & 250 & & & 350 & \\
\hline
\end{tabular}


De acordo com a Figura 4, o fluxo de caixa pode ser expresso em termos da Equação 1. A linha central da Figura 4 representa o período, a linha superior os valores de entrada e a linha inferior os valores de saída. As setas representam respectivamente as entradas de recursos financeiros (seta para cima) e a saída de recursos (seta para baixo). 0 controle de fluxo de caixa tem grande importância, pois facilita aos administradores tomarem decisões cruciais referentes ao investimentos financeiro com base em uma visão futura dos recursos da uma empresa (M ADEIRA, 2008).

\section{Equação 1:}

$V F=V P+(E-S)$

Onde VP significa valor presente, VF valor futuro, E Entrada de recursos financeiros e $\mathbf{S}$ saída de recursos.

Com base no fluxo de caixa é possível calcular a Taxa M ínima de Atratividade (TM A) para o empreendimento. Esse cálculo leva em consideração três fatores básicos: a) 0 custo de oportunidade; b) 0 risco do Negócio; c) A liquidez do negócio. A TM A é considerada pessoal e intransferível pois a propensão ao risco varia de pessoa para pessoa, ou ainda a TMA pode variar durante $o$ tempo. Dessa forma não há uma fórmula matemática determinística ou um algoritmo para calcular a TM A, sendo esta uma taxa subjetiva e empírica. É representada sob a forma de taxa de juros onde se pode considerar um investimento atrativo quando este, no mínimo, render o equivalente a esta taxa de juros desejada (NICHELLE JR., 2010).

0 Valor Presente Líquido (VPL) É um método de análise de investimentos onde se compara todas as receitas e despesas esperadas, utilizando a taxa mínima de atratividade imposta pelo investidor (CERVI et. al., 2010) e representada pela Equação 2.

\section{Equação 2. \\ $V P L=\frac{\sum_{n=1}^{N} B i-C i}{(1+T M A)^{n}}$}

Onde VPL é o valor presente líquido, $\mathbf{B}_{\mathbf{i}}$ São as receitas provenientes do empreendimento num dado momento, $\boldsymbol{C}_{\mathbf{i}}$ são os custos referentes aos empreendimento num dado momento, a taxa mínima de atratividade é definida em TMA e o período de tempo é definido por $\mathbf{n}$. Um investimento é considerado economicamente atrativo neste método quando o VPL for positivo, significando assim que 0 valor presente nas entradas de caixa é maior que 0 valor presente nas saídas de caixa. Quanto maior for o valor presente, mais atrativo é considerado o investimento.

Outro fator que deve ser calculado é Taxa Interna de Retorno (TIR) que é a taxa de juros onde o valor presente de todos os fluxos de entrada é igual ao valor presente de todos os fluxos de saída, ou seja, a TIR é a taxa que torna nulo o VPL de um investimento (CERVI et. al., 2010). A TIR deve ser comparada a TMA para verificar a rentabilidade do investimento. Para que um investimento seja considerado atrativo neste método é preciso que a TIR seja maior que a TMA (CERVI et. al., 2010). A Equação 3 apresenta o cálculo do TIR.

\section{Equação 3.}

$$
V P L=0=\text { InvestimentoInicial }+\frac{\sum_{i=1}^{N} B i-C i}{(1+T I R)^{t}}
$$


Por fim, o Payback é o método para saber o tempo de retorno de um investimento. Este método consiste simplesmente em quantificar, através do fluxo de caixa, o período necessário para recuperar o investimento feito inicialmente, ou seja, o momento em que o lucro líquido alcançado ao longo do tempo determinado se torna igual ao investimento inicial (CERVI et. al., 2010). A melhor forma de se calcular o retorno de investimento é através do método do payback descontado. Este método é semelhante ao payback simples, mas acrescenta no seu cálculo uma taxa de desconto antes de se proceder à soma dos fluxos de caixa. Em geral esta taxa de desconto será a TMA. Neste método, todos os fluxos de caixa futuro deverão ser descontados por esta taxa em relação ao perío do ao qual o fluxo está atrelado conforme apresentado na Equação 4.

\section{Equação 4.}

$V P t=\frac{B i-C i}{(1+T M A)}$

Onde $\mathbf{V} \mathbf{P}_{\mathbf{t}}$ é o valor presente do fluxo de caixa para um determinado período $\mathbf{t}$. Quando $\mathrm{VP}_{\mathrm{t}}$ for igual ao investimento inicial, t indicará a quantidade de tempo para o retorno do investimento.

\section{DISCUSSÃO DOS RESULTADOS}

\subsection{Ambiente de Estudo}

Para a análise do uso consorciado de fontes de energia alternativa na cadeia produtiva do frango de corte vai ser utilizado as características do aviário descrito em Sarmento et. al. (2015). 0 mesmo se localiza na cidade de Cacoal - RO e tem capacidade de confinamento de 30.000 aves. É do tipo Dark House e formado por uma construção em alvenaria de 120 metros de comprimento por 16 metros de largura $\left(1920 \mathrm{~m}^{2}\right)$. As aves ficam alojadas num período de aproximadamente 42 dias até 0 transporte para 0 abate, e é composto pelos seguintes equipamentos descritos na Tabela 1.

Tabela 1. Descrição dos Equipamentos Elétricos. Fonte: SARM ENTO et. al. 2015

\begin{tabular}{|l|ll|}
\hline Descrição & Quantidade & Potência \\
\hline M otor & 1 & $1,5(\mathrm{CV})-1,1 \mathrm{KW}$ \\
\hline M oto Bomba & 1 & $5(\mathrm{CV})-3,7 \mathrm{KW}$ \\
\hline M oto Bomba & 1 & $1,5(\mathrm{CV})-1,1 \mathrm{KW}$ \\
\hline M oto Bomba & 3 & $2(\mathrm{CV})-1,5 \mathrm{KW}$ \\
M oto Bomba & 1 & $3(\mathrm{CV})-2,2 \mathrm{KW}$ \\
Lampadas & 83 & $20 \mathrm{~W}-1,7 \mathrm{KW}$
\end{tabular}

O consumo médio anual desse aviário é de $58.015 \mathrm{kWh}$, que dividido pelos lotes produzidos (7 lotes ao ano) resulta num consumo de $8.287 \mathrm{kWh} /$ lote/ano. Isso significa um consumo de 0,276 kWh/ave (Sarmento et. al., 2015).

\subsection{Análise do Sistema Fotovoltaico}

Para suprir parte desse consumo de energia, por meio da energia solar fotovoltaica, é necessário fazer o dimensionamento do sistema. Um conjunto gerador fotovoltaico composto por placas solares, controladores de carga e inversores possui a característica de poderem ser montados de forma escalar. Ou seja, pode-se adquirir o sistema fotovoltaico como descrito na 
Figura 2 em módulos de forma a minimizar o custo inicial do sistema ou acrescentar a medida que a demanda de energia elétrica cresce.

0 município de Cacoal, Rondônia, distante 480 km de Porto Velho, está localizado na região norte nas coordenadas geográficas de $11^{\circ} 26^{\prime} 19^{\prime \prime}$ de latitude sul e $61^{\circ} 26^{\prime} 50^{\prime \prime}$ de longitude oeste. Uma fator importante a ser considerado quando se planeja o dimensionamento de um sistema fotovoltaico são as características climáticas da região. Nesse sentido alguns fatores são determinantes para essa caracterização, entre elas a Precipitação Média Anual da localidade onde vai ser montado o empreendimento solar, a Nebulosidade, a Insolação Média Total e a Temperatura Média anual. A Figura 5 apresenta a Precipitação Média Anual para o estado de Roraima (SANTOS, 2004). Esses valores são uma boa aproximação para a análise da região de Cacoal.

Da Figura 5, é possível observar que a região possui uma média de precipitação elevada, exceto para os meses de junho, julho e setembro. Essa característica climática é ruim para o sistema fotovoltaico, pois em condições de chuva o sistema não gera eletricidade, sendo obrigado a utilizar a energia da concessionária.

Figura 5. M édia de Precipitação Anual. Fonte SANTOS, 2004

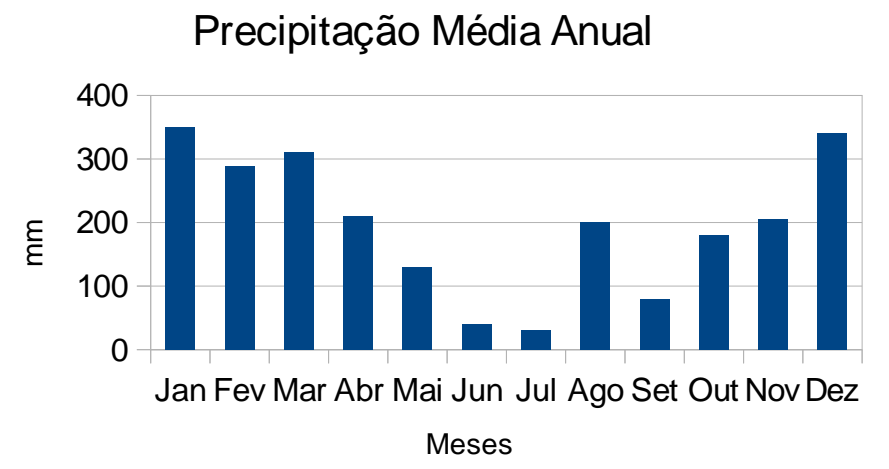

A Figura 6 representa a nebulosidade do estado de Rondônia (SANTOS, 2004). Esse fator é importante de ser observado pois caso o céu esteja coberto por nuvens, independente da ocorrência de chuvas na região, o processo de geração de eletricidade por meio do sistema fotovoltaico será prejudicado. Da análise da Figura 8, pode-se observar que a maior concentração de nuvens refere-se justamente aos meses de maior precipitação média anual, exceto para o mês de agosto.

Figura 6. Nebulosidade Média. Fonte SANTOS, 2004

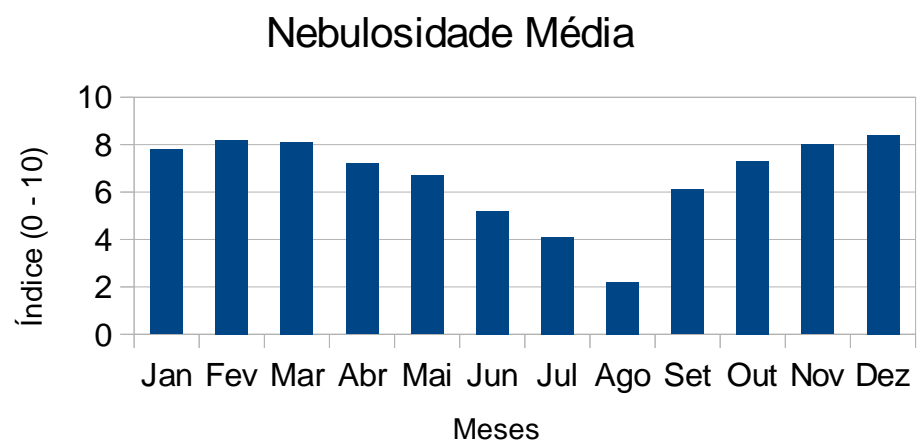

A Figura 7 
apresenta a Insolação Total, em termos de horas (SANTOS, 2004). Pode se observar que embora haja uma grande precipitação na região, com um elevado índice de nebulosidade, existe uma boa parcela de dias aproveitáveis para a geração de energia elétrica a partir do sistema fotovoltaico. Isso se deve também a uma característica da região norte do Brasil onde num dia claro, ocorre um breve período de chuva intensa, que após desaguar, volta o dia a abrir claro novamente.

Figura 7. Insolação Total em horas. Fonte SANTOS, 2004

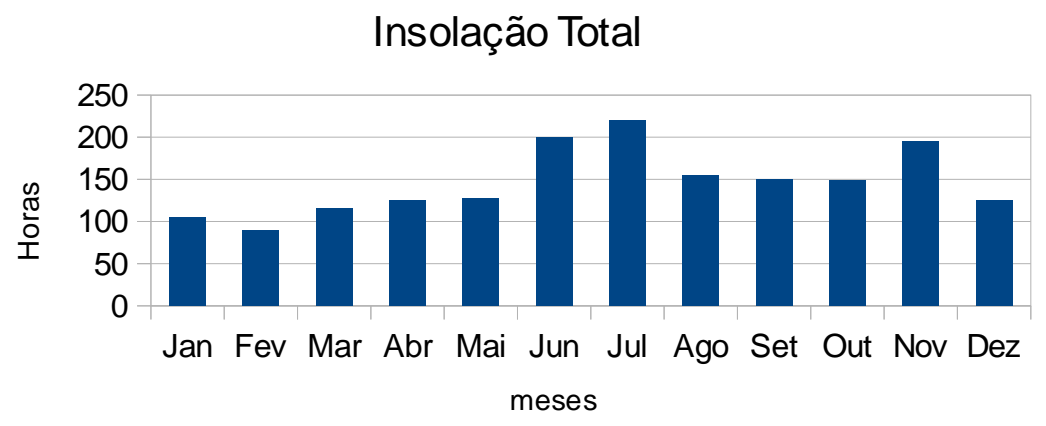

A Figura 8 apresenta a Média da Temperatura Anual (SANTOS, 2004). Esse dado é importante pois quanto maior a temperatura ambiente, menor é a eficiência dos painéis em converter a energia solar em eletricidade. É possível observar da Figura 8 que a média das temperaturas está compreendida entre 0 intervalo de 22 a $26{ }^{\circ} \mathrm{C}$. Essa é uma característica climática favorável para 0 uso da energia solar fotovoltaica, pois a temperatura padrão de operação (Inclusive para homologação das características de funcionamento do painel) é de $25^{\circ} \mathrm{C}$.

Figura 8. Temperatura M édia Anual. Fonte SANTOS, 2004

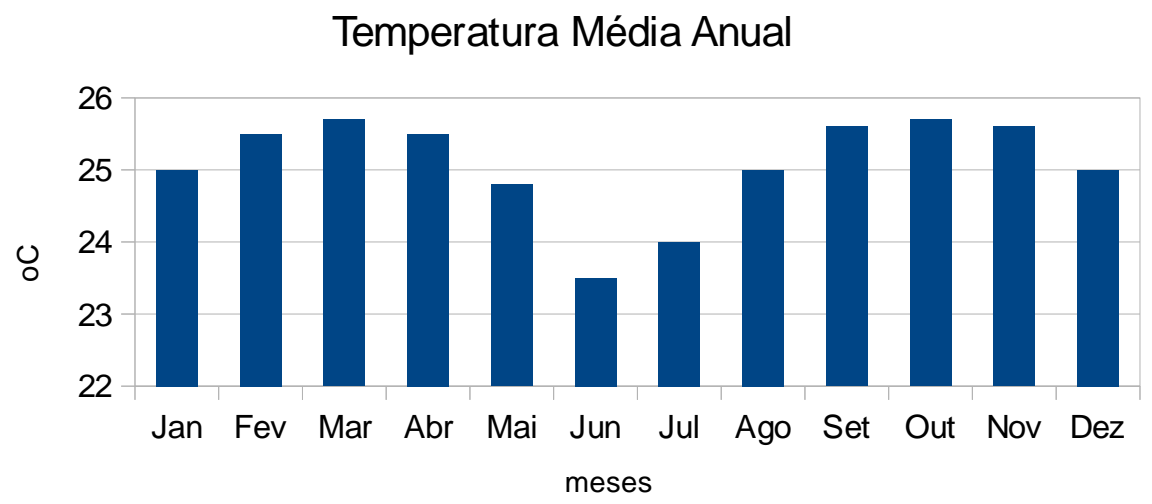

Considerando as características climáticas da região de Cacoal, foi proposto na Tabela 2 o cenário onde a energia solar fotovoltaica atende a pelo menos $25 \%$ do consumo mensal do aviário, ou seja, aproximadamente $1208 \mathrm{Wh} / \mathrm{mês}$. Nesse sentido o sistema fotovoltaico será dimensionado de forma que possa garantir essa produção de energia. Para que o mesmo possa ocorrer, ele será superdimensionado em 5\%, ou seja, uma produção de $1451 \mathrm{Kwh} /$ mês, ou o equivalente a 30\% do total. Essa medida visa garantir que mesmo em meses de menor incidência solar, maior precipitação pluviométrica e maior nebulosidade, ainda sim cerca de $25 \%$ da energia consumida pelo aviário seja gerada pelo sistema fotovoltaico. 
Tabela 2. Configuração de um sistema fotovoltaico para diferentes capacidades de fornecimento de energia

\begin{tabular}{|c|c|c|c|c|c|c|}
\hline PFSF $^{1}$ & $\begin{array}{l}\text { Wh/mê } \\
\text { s }\end{array}$ & $\begin{array}{l}\text { Potencia de } \\
\text { Pico } \\
(\mathbf{k W} \text { p) }\end{array}$ & $\begin{array}{l}\text { Número } \\
\text { painéis } \\
(260 \mathrm{~W})\end{array}$ & $\begin{array}{l}\text { de Área Mínima } \\
\text { Ocupada }\left(\mathrm{m}^{2}\right)\end{array}$ & $\begin{array}{l}\text { Preço Estimado do } \\
\text { Fotovoltaico } \\
\text { Controladores de } \\
\text { Inversores - em Reais) }\end{array}$ & $\begin{array}{r}\text { Sistema } \\
\text { (Painéis, } \\
\text { Carga, }\end{array}$ \\
\hline $30 \%$ & 1451 & 12,91 & 50 & 103,3 & 71.005 & \\
\hline
\end{tabular}

Conforme a descrição climática para a localidade de Cacoal realizada anteriormente, a produção da energia elétrica pelo sistema de geração fotovoltaica varia a cada mês. Essa variação é apresentada na Figura 9.

0 gráfico da Figura 9 apresenta a quantidade de energia gerada em Wh/mês, identificando claramente as variações entre os mesmos baseados nas características climáticas e geográficas da cidade de Cacoal. Já o gráfico da Figura 10 apresenta a informação da porcentagem de produção de energia excedente proposta de geração de $25 \%$ estipulada para o dimensionamento do uso da energia fotovoltaica. A produção de energia estimada para os meses e sua porcentagem excedente aos 1208 Wh é apresentado na Tabela 3.

Figura 9. Geração de Eletricidade a partir do Sistema Fotovoltaico para a localidade de Cacoal - RO.

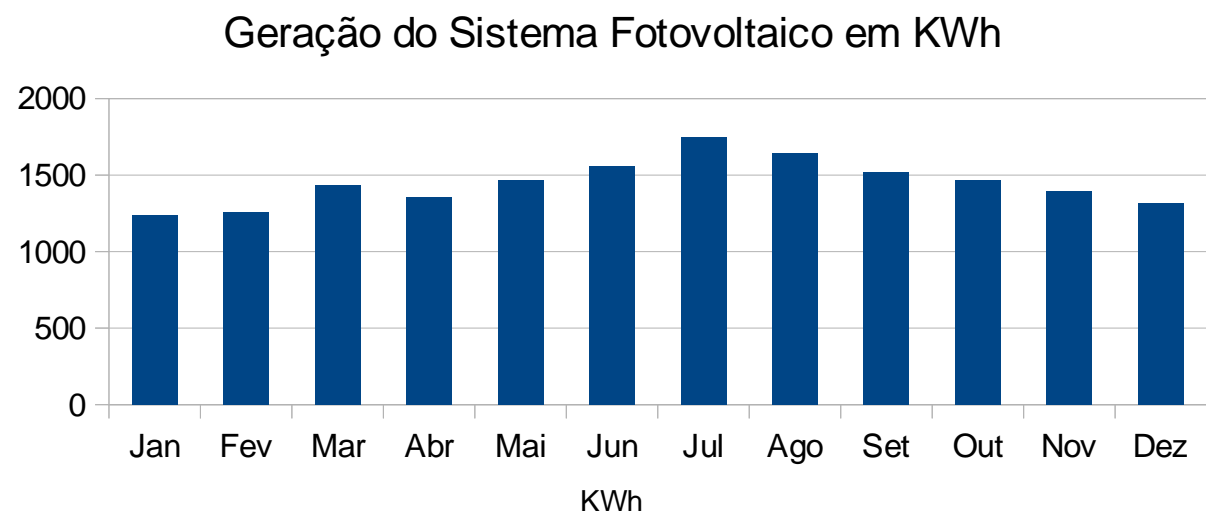

Figura 10. Percentual da produção elétrica excedente por mês.

\section{Percentural de Produção excedente}

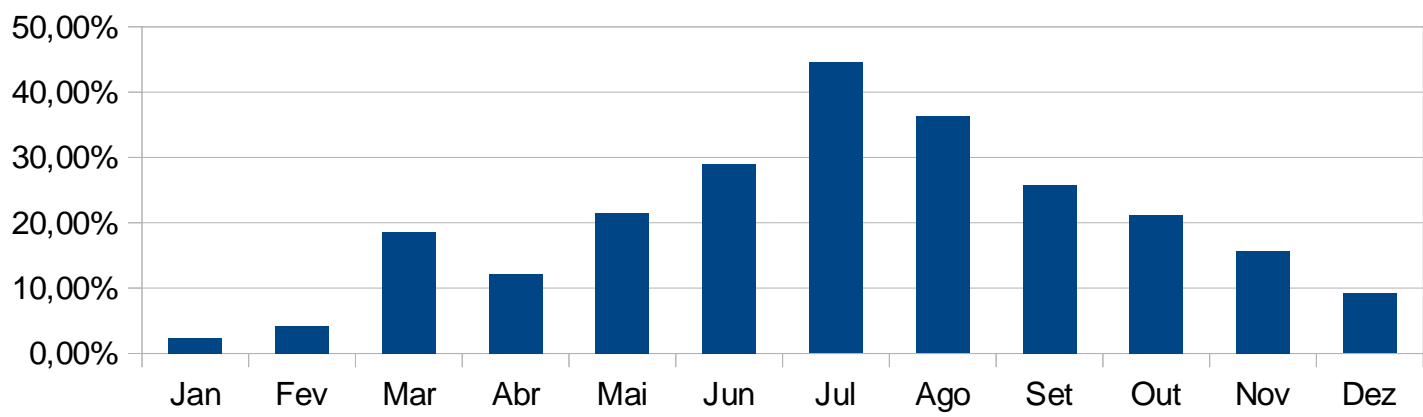

1 PFSF: Percentual de Energia Elétrica Fornecida pelo Sistema Fotovoltaico para a eletricidade consumida em um lote 
Tabela 3. Produção de Energia M ensal e Percentual Excedente

\begin{tabular}{|l|l|l|l|l|l|l|l|l|l|l|l|l|}
\hline Mês & JAN & FEV & M AR & ABR & MAI & JUN & JUL & AGO & SET & OUT & NOV & DEZ \\
\hline Wh & 1237 & 1259 & 1432 & 1354 & 1467 & 1558 & 1746 & 1646 & 1520 & 1464 & 1398 & 1319 \\
\hline$\%$ & 2,4 & 4,2 & 18,5 & 12,1 & 21,4 & 29,0 & 44,5 & 36,3 & 25,8 & 21,2 & 15,7 & 9,2 \\
\hline
\end{tabular}

\subsection{Análise do Sistema de Biomassa}

Como descrito em Sarmento et. al. (2015), esse aviário produz cerca de $195.300 \mathrm{~kg}$ de cama de frango por ano. (cerca de $27.900 \mathrm{~kg}$ de cama de frango por lote). Com base nesses dados foi dimensionado um biodigestor tipo tubular contínuo, com calha de água em alvenaria e com uma manta plástica como gasômetro. Suas dimensões são: largura de 6 metros $(\mathrm{m})$, comprimento $12 \mathrm{~m}$ e altura $1,68 \mathrm{~m}$ com custo estimado de $\mathrm{R} \$ 35.500,00$. Com essas especificações e a quantidade de cama de frango produzida, conforme descrito em Sarmento et. al. (2015) o biodigestor seria capaz de produzir cerca de 59,67 $\mathrm{m}^{3}$ de biogás por dia.

No trabalho de Sarmento et. al. (2015) foi proposto a utilização de um Grupo Gerador a Biogás (GGB) de $50 \mathrm{KVA}$, com valor estimado de compra em $\mathrm{R} \$ 65.000,00$, para suprir os equipamentos descritos na Tabela 1. Esse grupo gerador consome cerca de $25 \mathrm{~m}^{3}$ de biogás, 0 que Ihe dá uma autonomia de apenas 2 horas de funcionamento diários.

O GGB de 50 KVA é superdimensionado para o funcionamento do aviário, ou seja, possui uma potência excedente de 35\%, conforme descrito em Sarmento et. al. (2015). A potência efetivamente utilizada para suprir os equipamentos do aviário é portanto cerca de 32,5 KVA.

Com o uso em consórcio do sistema de geração fotovoltaica, dimensionado conforme apresentado nas tabelas 2 e 3, é possível redimensionar o grupo gerador para um sistema de menor potência e consumo, e ainda sim suprir o fornecimento de energia para os equipamentos da Tabela 1 e um excedente de segurança. Isso se deve ao fato que o sistema de geração fotovoltaica vai suprir no mínimo $25 \%$ da demanda de energia do aviário, ou seja, o gerador deve ser capaz de suprir os $75 \%$ da energia requisitada pelos equipamentos da Tabela 1 . Com esse senário, a potência efetivamente necessária a ser suprida pelo GGB no aviário será de 24,4 KVA.

A nova proposta para um GGB para atender esse aviário é de $30 \mathrm{KVA}$. Esse grupo gerador tem preço médio estimado em $R \$ 39.000,00$ e um consumo estimado de $15 \mathrm{~m}^{3}$ de biogás por hora. Esse modelo de gerador teria uma autonomia aproximada de 4 horas diárias, duas a mais que 0 modelo anterior. O GGB de $30 \mathrm{KVA}$ seria suficiente para suprir a demanda energética dos equipamentos (24,4 KVA) e ainda teria um excedente de produção de cerca de $18,6 \%$. Com uma autonomia de 4 horas de uso, o gerador seria um excelente escolha para sistema de backup em caso de falha na rede elétrica da concessionária.

Conforme descrito em Sarmento et. al. (2015) além do biogás, o biodigestor também produz o biofertilizante. Esse subproduto da conversão da cama de frango em biogás tem alto valor agregado e pode ser comercializado para complementar a renda do aviário. A massa do biofertilizante é estimada pela carga de entrada da cama de frango no biodigestor. Assim a estimativa de biofertilizante a ser produzida é de $195.300 \mathrm{~kg}$ por ano. O preço médio do biofertilizante na região da cidade de Cacoal é de $R \$ 150,00$ a tonelada (Sarmento et. al.,2015), sendo que a comercialização de todo o biofertilizante produzido pode gerar uma receita de $R \$$ $29.295,00$ bruto.

\section{4 análise financeira}

Independente dos benefícios trazidos pela implantação de sistemas de energia alternativa como a energia solar fotovoltaica, o biogás e o biofertilizante produzidos no biodigestor, a decisão para sua utilização só será determinada se, após uma análise financeira, for indicado a viabilidade econômica para o empreendimento. 
Conforme abordado no texto, os custos relativos da instalação do sistema solar, da construção do biodigestor e a aquisição de um GGB envolvem um grande investimento financeiro. A Tabela 4 apresenta os custos médios associados ao empreendimento.

Tabela 4. Custos diretos envolvidos na implantação do sistema de energia solar voto voltaica asso ciada ao uso do biodigestor

\begin{tabular}{|l|l|l|l|}
\hline Sistema & Valor (R\$) & $\begin{array}{l}\text { Porcentagem do custo do } \\
\text { projeto }\end{array}$ & $\begin{array}{l}\text { Tempo de vida útil dos } \\
\text { equipamentos }\end{array}$ \\
\hline $\begin{array}{l}\text { Sistema de Energiá } \\
\text { Fotovoltaico } \\
\text { controlador de carga, } \\
\text { inversores) }\end{array}$ & $71.005,00$ & $48,7 \%$ & Superior a 30 anos \\
\hline Biodigestor Tubular & $35.500,00$ & $24,3 \%$ & 20 anos \\
\hline GGB 30 KVA & $39.000,00$ & $26,8 \%$ & 10 anos \\
\hline Total: & $\mathbf{1 4 5 . 5 0 5 , 0 0}$ & $\mathbf{1 0 0 \%}$ & -- \\
\hline
\end{tabular}

Da Tabela 4 é possível observar que a maior parte do recurso financeiro é destinado ao sistema fotovoltaico. Porém esse sistema é que apresenta maior durabilidade em relação ao biodigestor tubular e ao GGB. Isso se deve ao fato do equipamento solar ser formato essencialmente por dispositivos eletrônicos, que se tiverem a manutenção adequada, pouco sofrem desgaste com o passar do tempo.

0 biodigestor possui uma vida útil estimada em 20 anos referente ao conjunto de alvenaria e ao conjunto do abrigo do GGB. Já a manta plástica do Biodigestor é estimada em 10 anos, segundo Cervi et. al. (2010), sendo necessária sua substituição após esse prazo.

O GGB por outro lado é um equipamento eletromecânico que possui muitas partes móveis e que exigirá uma manutenção muito mais severa e periódica. Seu tempo de vida útil é estimado em 10 anos e deve ser substituído dentro desses intervalos de tempo.

A Tabela 4 também fornece a informação do montante de investimentos a serem realizados. Esse valor imobilizado será abatido no tempo, conforme 0 uso do aviário requerer eletricidade desse conjunto gerador. 0 cálculo da economia anualizada gerada pelo sistema de energia alternativa é apresentada na Tabela 5.

Tabela 5. Economia de energia com o uso consorciado de energia solar fotovoltaica com biomassa.

\begin{tabular}{|l|ll|}
\hline Recurso Energético & Quantidade Wh/ano & $\begin{array}{l}\text { Porcentagem da energia } \\
\text { gerada }\end{array}$ \\
\hline $\begin{array}{l}\text { Energia Produzida no Sistema } \\
\text { Fotovoltaico }\end{array}$ & 17400,0 & $29,9 \%$ \\
\hline $\begin{array}{l}\text { Gerador GGB 30 KVA com 4 } \\
\text { horas de produção diária }\end{array}$ & 9968,1 & $17,1 \%$ \\
\hline Total & 27068,1 & $47,0 \%$ \\
\hline
\end{tabular}

Considerando o custo da energia anual em $\mathrm{R} \$ 16.186,00$ para um consumo de $58.015 \mathrm{Wh}$ de energia, e que a instalação dos equipamentos de energia alternativa vão proporcionar uma economia estimada de $27.068,1 \mathrm{Wh}$, esse valor representa cerca de $47 \%$ do consumo total. 0 que em termos financeiros equivale a $\mathrm{R} \$ 7.607,42$ anuais. 
Para a análise da viabilidade econômica do empreendimento será analisado um período de 10 anos. Isso devido ao fato da depreciação do GGB e da manta plástica do biodigestor ter atingido sua vida útil. Sendo necessária a sua substituição para um novo ciclo de operação. Será considerado também um reajuste anual médio de $5 \%$ no valor da energia elétrica. Esse índice é compatível com o histórico de aumentos tarifários autorizados pela Agência Nacional de Energia Elétrica - ANEEL.

Assim, para o período proposto na análise, o consumo de energia elétrica para o produtor sem 0 uso de fontes alternativas de energia seria de aproximadamente $R \$ 229.951,00$. A economia gerada pelo uso consorciado pelo sistema solar com o biodigestor seria de cerca de R\$ 108.077,00. Assim o produtor pagaria efetivamente a concessionária elétrica no período de 10 anos cerca de $\mathrm{R} \$ 121.874,00$.

Também deve ser levado em consideração o valor da venda do biofertilizante, subproduto da geração do biogás. Nesse perío do de avaliação a receita bruta da venda do biofertilizante seria de aproximadamente $\mathrm{R} \$ 367.903,00$. Foi considerado também uma atualização anual do preço do biofertilizante na ordem de $5 \%$.

Para a analise financeira do empreendimento e verificação da sua viabilidade deve-se determinar a Taxa M ínima de Atratividade, que seria se o dinheiro fosse aplicado no período de 10 anos num investimento financeiro ao invés da melhoria da granja. Neste trabalho, serão considerados uma TMA de $8,5 \%$ aa (ao ano) e $11 \%$ aa que representam respectivamente 0 rendimento médio da Caderneta de Poupança e do Tesouro Direto. Essas taxas são compatíveis com os rendimentos das aplicações conservadoras e representam uma aplicação de longo prazo com baixíssimo risco.

Com esses dados é possível calcular a partir da Equação 20 valor presente presente financeiro do empreendimento após o período de 10 anos em $\mathrm{R} \$ 153.252,82$. Somado com a venda de biofertilizante, esse montante pode alcançar o valor de R\$521. 155,82. Ou seja, um retorno financeiro positivo frente ao investimento realizado no pagamento exclusivamente da energia elétrica. Da Equação 3 é possível calcular a Taxa Interna de Retorno (TIR) do Investimento para o período de 10 anos. Nesse sentido o valor encontrado foi de uma taxa de 11,21\% se considerado a comercialização do biofertilizante. Por fim, o tempo de retorno do investimento (Payback), a partir da TM A definida é apresentada na Tabela 6.

Tabela 6. Resultado do Payback Simples e Payback Descontado para o período de 10 anos

\begin{tabular}{|l|l|ll|}
\hline TMA (\%) & TIR (\%) & $\begin{array}{l}\text { Payback simples } \\
\text { anos) }\end{array}$ & $\begin{array}{l}\text { (em Payback descontado } \\
\text { (em anos) }\end{array}$ \\
\hline 8,5 & 11,21 & 6,18 & 8,63 \\
\hline 11,0 & 11,21 & 6,18 & 9,88 \\
\hline
\end{tabular}

\section{CONCLUSÃO}

Observando a análise financeira realizada é possível verificar que o empreendimento se paga dentro do prazo estimado de 10 anos, conforme o payback apresentado na Tabela 6. Mas é necessário considerar que esse resultado só será possível se houver a comercialização do biofertilizante. Isso por que devido ao fato do tempo de vida útil da manta do biodigestor e do GGB ser de apenas 10 anos, um novo investimento na ordem de $50 \%$ do investimento original deve ser realizado a cada novo ciclo de 10 anos. Já o sistema fotovoltaico possui um ciclo de vida na ordem três vezes maior que o ciclo de vida da manta do biodigestor e do GGB. Dessa forma seu custo não será contabilizado nos próximos 2 ciclos.

Outro ponto importante a se considerar é o fato dessa análise não considerar os custos de manutenção do sistema de biodigestor e do GGB. Essa manutenção é periódica e possui um custo 
elevado. Já o sistema fotovoltaico praticamente não exige manutenção e esse custo é praticamente nulo no período de 10 anos.

Outra questão que deve ser levada em consideração é o mercado de biofertilizante para a região de Cacoal - RO. Uma análise desse mercado se faz imprescindível, pois uma parte considerável da renda do sistema de geração de energia e da granja em si passa a depender desse produto.

Da mesma forma é importante considerar o fato de que o GGB pode funcionar como um sistema de backup fornecendo eletricidade para cerca de $75 \%$ dos equipamentos da granja no caso de falhas no fornecimento de energia da concessionária elétrica por um período de até 4 horas. Já o sistema de energia fotovoltaica pode manter cerca de $25 \%$ das instalações em uso durante 0 dia por cerca de 6 a 8 horas dependendo do mês do ano. Assim o produtor minimiza as chances da perdas de um lote de produção de frango de corte no caso de falha no fornecimento da concessionária de energia, o que representaria graves prejuízos financeiros para o mesmo como compromissos assumidos perante fornecedores e quebras de contratos de exportação entre outros.

Por fim, foi demonstrado por meio da análise financeira que viabilidade econômica do empreendimento é atrativa, uma vez que a taxa de retorno interna (TIR) em 11,21\% aa supera a de investimentos tradicionais como a poupança $(8,5 \%$ aa) e do tesouro direto ( $11 \%$ aa) funcionando não só como uma forma de diminuir os gastos com a energia elétrica, mas também gerando novas receitas e permitindo ao produtor diversificar o mix de produtos comercializad os pela granja.

\section{REFERÊNCIAS}

AES Eletropaulo. Relatório de eventos em situação de emergência. No. 20160310_COBRADE_TODOS. São Paulo. 2016.

BRASIL, Newton Paterman. Cogeração de Energia. Curso de Engenharia de Equipamentos. 2005.

CERVI, R. G. Avaliação econômica do aproveitamento do biogás e biofertilizante produzido por biodigestão anaeróbia: estudo de caso em unidade biointegrada. 2009. 67 f. Dissertação (M estrado em Energia na Agricultura) - Faculdade de Ciências Agronômicas, Universidade Estadual Paulista, Botucatu, 2009.

CERVI, Ricardo G.; ESPERANCINI, Maura S. T.; BUENO, Osmar de C. Viabilidade econômica da utilização do biogás produzido em granja suinícola para geração de energia elétrica. Revista Engenharia Agrícola, Jaboticabal, Out 2010, vol.30, no.5, p.831-844. ISSN 0100-6916.

FERREIRA, Regis de Castro. Instalações para Aves. Escola de Agronomia e Engenharia de Alimentos - Setor de Engenharia Rural. Universidade Federal de Goiás. 2015.

IBGE. Indicadores IBGE: Estatísticas da produção pecuária. Setembro de 2016.

MADEIRA, Jonas Reis. Fluxo de caixa: A importância desta ferramenta na gestão empresarial. São Paulo. 2008.

MATOS, Fernando B. Modelamento computacional do comportamento de células fotovoltaicas baseadas nas propriedades físicas dos materiais. 125f. Dissertação de Mestrado. Universidade Federal de Uberlândia. Uberlândia - M G. 2006. 
NICHELLE JR., Paulo. Análise de eficientização energética e uso de fontes de energia renováveis em uma granja de recria de aves. Trabalho de Conclusão de Curso. Universidade Federal do Paraná. 2010.

R3 Técnica Brasil. Disponível em «ttp://www.r3brasil.com.br/2015/01/energia-solar.html> acessado em 24/02/2017.

SANTOS, Nilson. Climatologia de Rondônia. Universidade Federal de Rondônia. 2004. ISSN. 15175421.

SARM ENTO, Zito R.; NAZÁRIO, Carlos A. S.; CARNeIRO, Paulo H. G.; NAZÁRIO, Ségio L. S. Aproveitamento do potencial energético da cama de frango para uso na atividade avícola. XI Congresso Nacional de Excelência em Gestão. 2015. ISSN: 1984-9354. 